\title{
Applying Social Network Indicators in the Analysis of Verbal Aggressiveness at the School
}

\author{
Dimitrios Theocharis, Alexandra Bekiari \\ Department of Physical Education and Sports, University of Thessaly, Thessaly, Greece \\ Email: theoj2009@gmail.com
}

How to cite this paper: Theocharis, D. and Bekiari, A. (2017) Applying Social Network Indicators in the Analysis of Verbal Aggressiveness at the School. Journal of Computer and Communications, 5, 169-181. https://doi.org/10.4236/jcc.2017.57015

Received: April 30, 2017

Accepted: May 22, 2017

Published: May 25, 2017

Copyright $\odot 2017$ by authors and Scientific Research Publishing Inc. This work is licensed under the Creative Commons Attribution International License (CC BY 4.0).

http://creativecommons.org/licenses/by/4.0/

\section{(c) (i) Open Access}

\begin{abstract}
The purpose of this study is to detect structures of verbal aggressiveness using multiple indicators of social networks analysis (out- and in-degree, pagerank, Katz, authority, incremental and proportional behavior). Standardized questionnaires have been distributed to 151 students and 45 teachers at primary and secondary schools. We performed complete analysis of social networks and further processing by applying principal component analysis. According to the results, a complex structure of verbal aggressiveness occurred in the classes (networks) and the structure was necessary to be explored with several network indicators (Katz, pagerank, incremental and proportional behavior etc.). Prejudices about the role of the gender in the aggressiveness (e.g. that female are more peaceful than male) are deconstructed. As for the typology of the incremental and proportional behavior two types were proposed: 1) the "personal attack" that the verbal aggressor aims the victim's personality and 2) "social exclusion" that the strategy is to exclude the victim from the social surrounding.
\end{abstract}

\section{Keywords}

Verbal Aggressiveness, Network Analysis, Typology

\section{Introduction}

[1] has defined verbal aggressiveness as an attack in the perception of the individual to cause emotional pain to a person through communication process. Verbal aggressiveness is considered to be a destructive feature of communication [2]-[7] and acts as a catalyst for physical aggressiveness [8]. Research indicated that teachers' verbal aggressiveness is negatively correlated with students' attendance and participation in the learning process [7] [9], student motivation [10] [11] [12] [13] [14], interest [15], self-esteem [1] [16] [17], behaviour, thinking and motivation [18] [19] [20] [21], satisfaction, and learning outcome [7] [10] 
[21]-[29], students' affective learning [30] [31] [32], teacher's reliability [33] and discipline reasons [34] [35]. Also, verbal aggressiveness affects student-teacher communication [11] [16] [36] [37], interpersonal attraction [38], students' fair play behaviours [39], Machiavelian tactics [40], bullying [41] and classroom climate [21] [42] [43]. Teachers with a high level of verbal aggressiveness present a high level of burnout [29] [44]. Verbal aggressiveness has also been examined through network analysis, and they have revealed hierarchical structures of aggressiveness behavior [20] [45] [46] [47] [48] [49].

Purpose of this study is to detect structures of verbal aggressiveness using multiple indicators of social networks analysis (out- and in-degree, pagerank, Katz, authority, incremental and proportional behavior). Especially, incremental and proportional behaviors are newly suggested indicators [47] which are expected to make deeper structures discernible.

The theoretical added value of this research consists in examples of detection and exploration of determinants of the verbal aggressiveness through multiple network indicators, the most newly suggested of which are the incremental and proportional behavior. Different network indicators depict different structures (relations) of behavior among the students and teaching staff. Thus, only e.g. indegree or Katz, cannot reveal any possible hierarchy of verbal aggressiveness. Incremental and proportional behaviors depict two types of over-extroversion (idiosyncratic and strategic, respectively, according to [47]), which here is first time applied at school classes. The practical added value consists in the using of the results for more accurate consulting and pedagogic action in the classes. In this way, possible prejudices can be deconstructed.

\section{Method}

\subsection{Network Analysis}

Complete network analysis investigates the interactions of participants through appropriate indicators depicting structures [50] [51]. Visone software has calculated the following indicators through network analysis:

1) In-degree (occasional hierarchy) is an indicator of centrality and defined as the percentage of relations which ends in a node. It shows a superficially targeted person.

2) Out-degree (occasional hierarchy, inversely to the in-degree) is an indicator of centrality and defined as the percentage of outgoing relations of a node. It shows a superficially aggressive person.

3) Katz status (accumulative hierarchy) calculated as power series through successive chains. It indicates passiveness more deep-rooted than in-degree.

4) Pagerank (distributive hierarchy) is based on the transferred value from one node to others. It is similar to Katz status, but it constrains outliers.

5) Authority indicates the nodes which are attracting most links from other nodes, among those who intensively seek to maintain relationships. In this case, it reveals a distinct tendency of being targeted.

All indicators above have repeatedly been used and interpreted in real empir- 
ical context in many researches [46] [48] [52]-[57].

Additionally, two new indicators were proposed at recent research [47]. These two reveals over-extroversion, in contrast to the afore-mentioned indicators which do not take into account the relation between outgoing aggression (outdegree) and incoming aggression (indegree, katz, pagerank, authority). Namely, they consider the relation between targeting others and being targeted by others.

1) Incremental behavior $(I B)$ indicates the pure aggressiveness and was computed by the following formula.

$$
I B=(4 \times \text { outdegree })-(\text { indegree }+ \text { status }+ \text { pagerank }+ \text { authority })
$$

2) Proportional behavior $(P B)$ expresses rational strategy of adaptability

$$
P B=\frac{4 \times \text { outdegree }+1}{\text { indegree }+ \text { status }+ \text { pagerank }+ \text { authority }+1}
$$

\subsection{Sampling}

Seven classes of public primary and secondary schools (Gymnasium and Lyceum) in Trikala have been surveyed as network samples. Cluster sampling has been used [58] and each class was examined as a network, where the students were the nodes, and the links among them were the perceived verbal aggressiveness to each other. The sample consisted of 196 individuals. The questionnaires were fluently completed within 30 - 45 minutes. The anonymity of the informants was emphasized and the participation was voluntary. At Tables 1-3, basic descriptive information about the sample is presented. In Table 1, a relatively balanced share of genders is observed while the relation of teachers to students is about $1 / 3$.

Table 1. Distribution of sample by the gender.

\begin{tabular}{cccc}
\hline Gender & Students & Teachers & Total \\
\hline Famale & 70 & 21 & 91 \\
Male & 81 & 24 & 105 \\
Total & 151 & 45 & 196 \\
\hline
\end{tabular}

Table 2. Distribution of sample by the networks and gender.

\begin{tabular}{ccccc}
\hline \multirow{2}{*}{ Network } & & \multicolumn{3}{c}{ Gender } \\
\cline { 2 - 5 } & Type of school & Female & Male & Total \\
\cline { 2 - 5 } A & Primary school & 13 & 12 & 25 \\
B & Secondary school (Gymnasium) & 14 & 16 & 30 \\
C & Secondary school (Gymnasium) & 9 & 20 & 29 \\
D & Secondary school (Gymnasium) & 19 & 10 & 29 \\
E & Secondary school (Gymnasium) & 10 & 19 & 29 \\
F & Secondary school (Lyceum) & 10 & 16 & 26 \\
G & Secondary school (Lyceum) & 16 & 12 & 28 \\
Total & & 91 & 105 & 196 \\
\hline
\end{tabular}


Table 3. Distribution of sample by the networks and ages.

\begin{tabular}{ccc}
\hline Network & Students' Age & Range of teachers' age \\
\hline A & 11 & 54 \\
B & 14 & $45-55$ \\
C & 14 & $45-55$ \\
D & 14 & $45-56$ \\
E & 13 & $45-55$ \\
F & 17 & $46-63$ \\
G & 17 & $46-63$ \\
\hline
\end{tabular}

In Table 2, though, the relation between female and male at the network from $\mathrm{C}$ to $\mathrm{G}$ is not so balanced. This produces the advantage of a gender-based dynamics which may intensify the network effect.

In Table 3, a smooth increase of the students' age is observed through the networks, from A to $\mathrm{G}$. This assures the research advantage of covering a wide range of age. This also happens in the case of teachers, whose age classes are also smoothly increasing.

\subsection{Questionnaire}

The participants answered a questionnaire consisted of two parts: 1) non-network variables (e.g. gender, age, economic situation, etc.), and 2) network variables based on the Greek version of Verbal Aggressiveness Scale [59] which consisted of eight items (e.g., "threats students" "makes negative judgments of ability"). Preliminary examination [59] supported the psychometric properties of the instrument. In particular, Confirmatory Factor Analysis indicated satisfactory fit indices (CFI: 0.97, SRMR: 0.02), and internal consistency of the scale $(\alpha=0.96)$.

\subsection{Statistical Analysis}

Visone (version 2.17) was used for the computation of several indicators (indegree, status, pagerank, authority, density, avg network degree). Also, the structure of the networks was depicted by Visone software. Both network and non-network data were entered into Statistical Package for Social Sciences (SPSS 21.0). The Spearman correlation coefficient was used to measure the correlation between the network non-network variables. Principal Component Analysis was implemented to formulate typology for the Incremental and Proportional behavior. The level of statistical significance was set at 0.05 .

\section{Results and Discussion}

\subsection{Examples of Structures in Verbal Aggressiveness}

In Figure 1 the seven networks of verbal aggressiveness are depicted and classified by density. All graphs visualize the katz hierarchy of the networks. The red nodes represent female and the blue ones male. The shape of circle at a node 

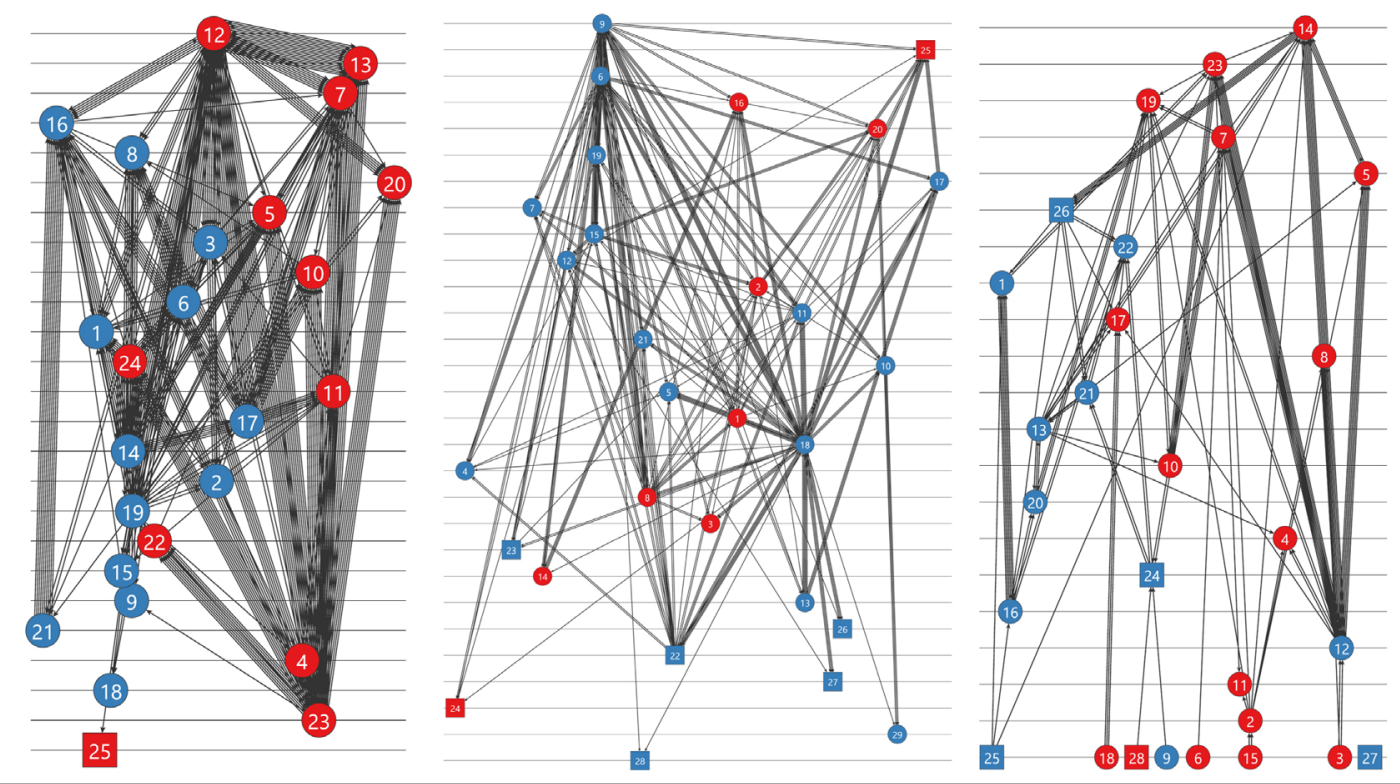

\begin{tabular}{|c|c|c|c|}
\hline Network & A & C & G \\
\hline Density & 0.38 & 0.33 & 0.16 \\
\hline Avg. Degree & 33.36 & 21.24 & 9.21 \\
\hline Avg in-/out degree & 16.68 & 10.62 & 4.60 \\
\hline Age of pupils (years) & 11 & 14 & 17 \\
\hline
\end{tabular}
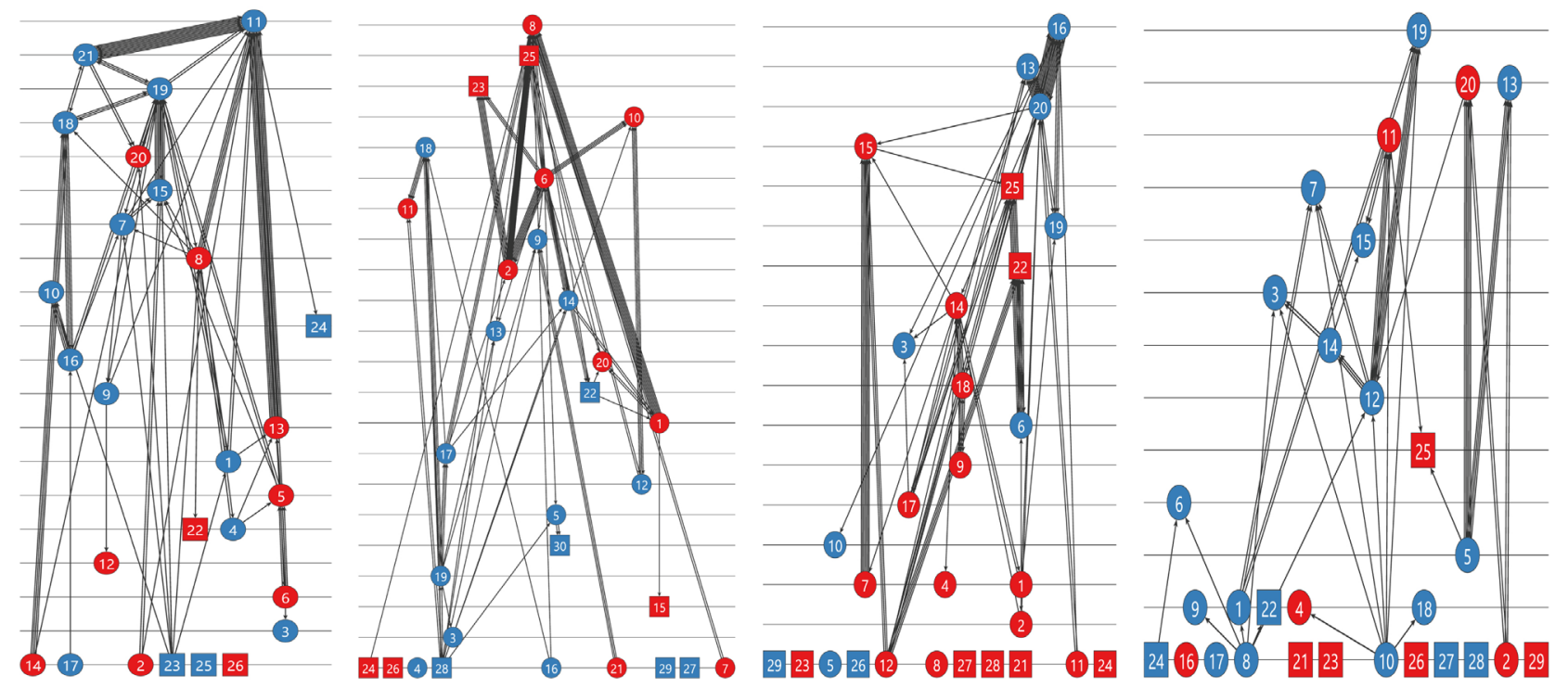

\begin{tabular}{|c|c|c|c|c|}
\hline Network & F & B & D & E \\
\hline Density & 0.16 & 0.12 & 0.09 & 0.07 \\
\hline Avg Degree & 8.30 & 7.9 & 6.62 & 3.65 \\
\hline Avg in-/outdegree & 4.15 & 3.9 & 3.31 & 1.8 \\
\hline Age of students (years) & 17 & 14 & 14 & 13 \\
\hline
\end{tabular}

Figure 1. Verbal aggressiveness hierarchy in different networks according to Katz indicator.

implies that the participant is student and the rectangle that is teaching staff. At the top of the status hierarchy there can be either male or female nodes. 

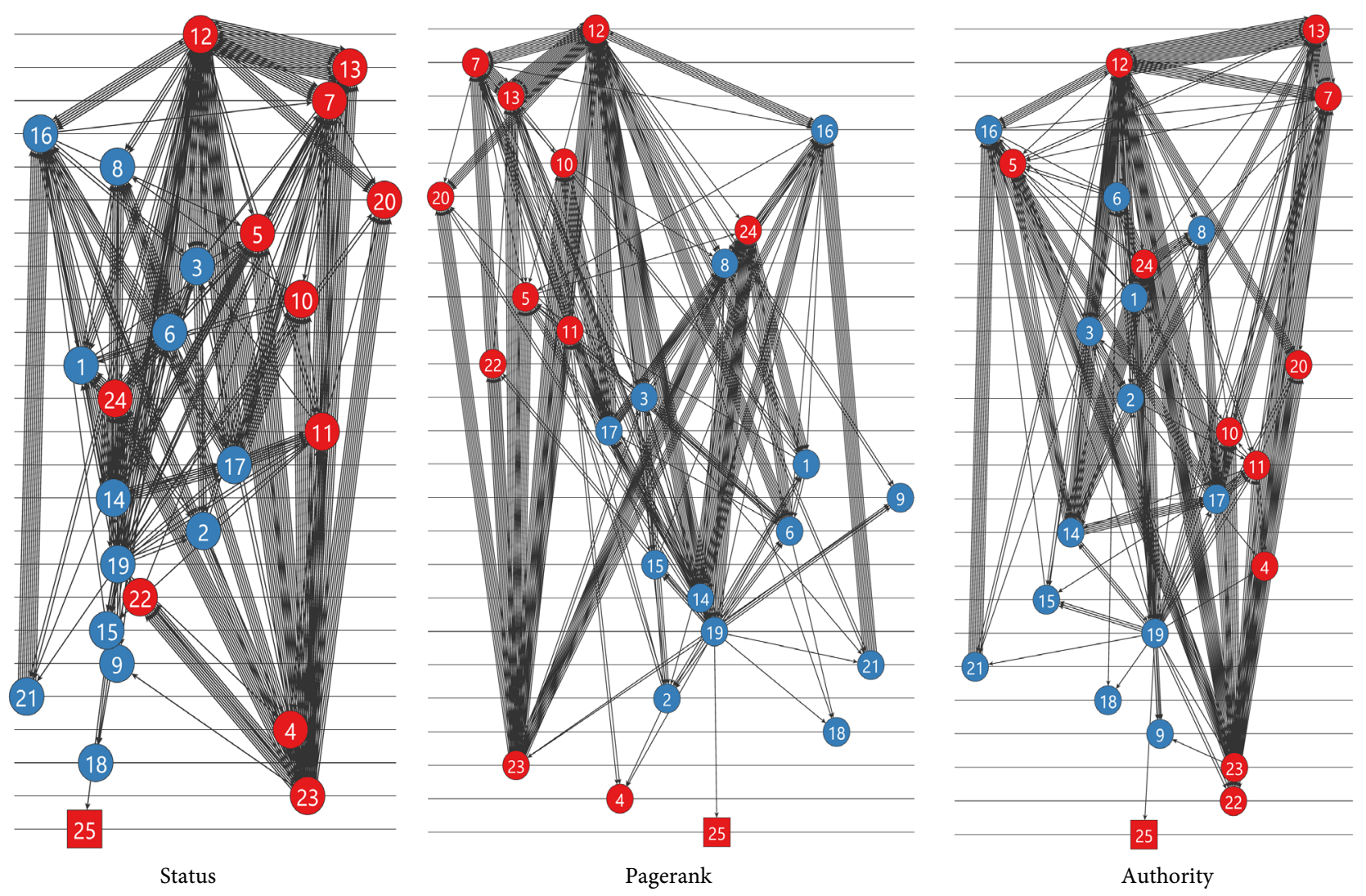

Figure 2. Verbal aggressiveness hierarchy in network A according to different indicators.

This is a rough evidence that verbal aggressiveness is not strongly affected by the gender.

Also, the density varies among networks and seems to be correlated with the average degree of the network and with the ratio of in-degree to out-degree.

In Figure 2 a network is analyzed and visualized by different indicators. The structure of the networks does not seem to alter at least at the peak while at the bottom, there is a slight differentiation.

\subsection{Relationship between Verbal Aggressiveness}

In Table 4 the correlations among different indicators of underestimating of intelligence (item of verbal aggressiveness, selected as an example), age and gender are presented. The gender, as showed above on the basis of rough visual evidence mentioned above in Figure 1, does not play any role in verbal aggressiveness while the higher age conctitute someone a target of aggressiveness in contrast to previous research results referring to Hgiher Education students [46] [48]. However, the age plays also no role idiosyncratically (IB) or strategically (PB).

In Table 5, correlations between total verbal aggressiveness, age and gender. Once again, gender does not seem to have any significant correlation with any of the indicators. Age seems to be correlated with most of the indicators (depitcting either incoming and outgoing ones), however, once again not with IB and PB. 
Table 4. Spearman correlations of verbal aggressiveness (underestimating of intelligence).

\begin{tabular}{cccccccc}
\hline $\begin{array}{c}\text { Spearman's } \\
\text { rho }\end{array}$ & Status & Pagerank & Indegree & Authoriy & Outdegree & IB & PB \\
\hline Gender & 0.050 & 0.115 & 0.039 & 0.064 & -0.020 & -0.098 & -0.037 \\
& 0.487 & 0.107 & 0.589 & 0.376 & 0.784 & 0.171 & 0.610 \\
Age & 0.140 & $\mathbf{0 . 2 3 0 ^ { * * }}$ & 0.139 & $\mathbf{0 . 1 6 4}$ & 0.116 & -0.086 & -0.058 \\
& 0.063 & $\mathbf{0 . 0 0 2}$ & 0.066 & $\mathbf{0 . 0 3 0}$ & 0.125 & 0.256 & 0.444 \\
\hline
\end{tabular}

${ }^{*}$ Correlation is significant at the 0.01 level $\left(2\right.$-tailed) ${ }^{*}$ Correlation is significant at the 0.05 level (2-tailed).

Table 5. Spearman correletions of verbal aggresiveness (total).

\begin{tabular}{ccccccccccc}
\hline $\begin{array}{c}\text { Spearman's } \\
\text { rho }\end{array}$ & Gender & Age & Status & Pagerank Indegree Authoriy Outdegree & IB & PB \\
\hline Gender & 1.000 & 0.025 & 0.085 & 0.094 & 0.079 & 0.025 & 0.048 & 0.019 & -0.011 \\
&. & 0.739 & 0.237 & 0.192 & 0.269 & 0.727 & 0.505 & 0.794 & 0.880 \\
Age & 0.025 & 1.000 & $\mathbf{0 . 2 6 8 ^ { * * }}$ & $\mathbf{0 . 2 6 2 * *}$ & $\mathbf{0 . 2 7 7 ^ { * * }}$ & $\mathbf{0 . 3 9 8 ^ { * * }}$ & $\mathbf{0 . 1 5 0 ^ { * }}$ & -0.070 & -0.059 \\
& 0.739 &. & $\mathbf{0 . 0 0 0}$ & $\mathbf{0 . 0 0 0}$ & $\mathbf{0 . 0 0 0}$ & $\mathbf{0 . 0 0 0}$ & $\mathbf{0 . 0 4 7}$ & 0.353 & 0.439 \\
\hline
\end{tabular}

${ }^{*}$ Correlation is significant at the 0.01 level $\left(2\right.$-tailed) ${ }^{*}$ Correlation is significant at the 0.05 level (2-tailed).

\subsection{Typology of Verbal Aggressiveness Based on Incremental and Proportional Indicators}

In Table 6, a principal component analysis (PCA) is presented which was conducted on the nine items verbal aggressiveness (incremental behavior). The Kaiser-Meyer-Olkin measure verified the sampling adequacy for the analysis, $\mathrm{KMO}=0.69$, and all $\mathrm{KMO}$ values for individual items were lower than 0.55 , which is above the acceptable limit of 0.5 [60]. Bartlett's test of sphericity $\chi^{2}(45)=$ 293.2, p $<0.001$, indicated that correlations between items were sufficiently large for PCA. An initial analysis was run to obtain eigenvalues for each component in the data. Two components had eigenvalues over Kaiser's criterion of 1 and in combination explained $81.92 \%$ of the variance. Table 6 shows the factor loadings. The items that cluster on the same components suggest that component 1 represents a "Personal attack", component 2 "social exclusion".

In Table 7, a principal component analysis (PCA) on the nine items verbal aggressiveness (Proportional behavior) is presented. The Kaiser-Meyer-Olkin measure verified the sampling adequacy for the analysis, $\mathrm{KMO}=0.75$, and all KMO values for individual items were above 0.70 , which is well above the acceptable limit of 0.5 [60]. Bartlett's test of sphericity $\chi^{2}(45)=496.18, \mathrm{p}<0.001$, indicated that correlations between items were sufficiently large for PCA. An initial analysis was run to obtain eigenvalues for each component in the data. Two components had eigenvalues over Kaiser's criterion of 1 and in combination explained $92.31 \%$ of the variance. Table 7 shows the factor loadings. The items that cluster on the same components suggest that component 1 represents a "Personal attack", component 2 "social exclusion".

Both indicators compare the outgoing with ingoing verbal aggressiveness. 
Table 6. Typology of verbal aggressiveness (Incremental behavior).

\begin{tabular}{ccc}
\hline Component Matrix $^{\mathrm{a}}$ & \multicolumn{2}{c}{ Component } \\
\cline { 2 - 3 } Incremental behavior (IB) & Personal attack & Social exclusion \\
\hline Verbal aggressiveness (insulting behavior) & $\mathbf{0 . 8 5 5}$ & -0.156 \\
Verbal aggressiveness (underestimating of intelligence) & $\mathbf{0 . 7 3 1}$ & $\mathbf{0 . 4 9 8}$ \\
Verbal aggressiveness (underestimated attitude) & $\mathbf{0 . 9 3 9}$ & 0.111 \\
Verbal aggressiveness (ironic comments) & $\mathbf{0 . 9 0 4}$ & 0.047 \\
Verbal aggressiveness (rude behavior) & $\mathbf{0 . 7 8 4}$ & 0.179 \\
Verbal aggressiveness (lessening behavior) & $\mathbf{0 . 8 9 2}$ & -0.341 \\
Verbal aggressiveness (causing bad feelings) & $\mathbf{0 . 8 8 5}$ & 0.031 \\
Verbal aggressiveness (mocking behavior) & $\mathbf{0 . 9 0 7}$ & -0.226 \\
Verbal aggressiveness (threating behaviour) & $\mathbf{0 . 8 3 1}$ & -0.282 \\
Verbal aggressiveness & & 0.955 \\
(rejection from social surroundings) & 0.209 & \\
\hline
\end{tabular}

Extraction method: Principal component analysis.

Table 7. Typology of verbal aggressiveness (Proportional behavior).

\begin{tabular}{ccc}
\hline Component Matrix $^{\mathrm{a}}$ & \multicolumn{2}{c}{ Component } \\
\cline { 2 - 3 } Proportional behavior (PB) & Personal attack & Social exclusion \\
\hline Verbal aggressiveness (insulting behavior) & 0.985 & -0.100 \\
Verbal aggressiveness (underestimating of intelligence) & 0.709 & 0.662 \\
Verbal aggressiveness (underestimated attitude) & 0.929 & -0.019 \\
Verbal aggressiveness (ironic comments) & 0.974 & -0.048 \\
Verbal aggressiveness (rude behavior) & 0.907 & 0.102 \\
Verbal aggressiveness (lessening behavior) & 0.936 & -0.167 \\
Verbal aggressiveness (causing bad feelings) & 0.975 & -0.063 \\
Verbal aggressiveness (mocking behavior) & 0.939 & -0.122 \\
Verbal aggressiveness (threating behavior) & 0.951 & -0.133 \\
Verbal aggressiveness & & 0.992 \\
(rejection from social surroundings) & & 060 \\
\hline
\end{tabular}

Extraction method: Principal component analysis.

They indicate pure aggressiveness [47]. So the typology can reveal the strategies of a verbal aggressor. A verbal aggressor either attack to the victim's personality with a different pattern or simple try to exclude him from social surrounding. Such typologies have also been proposed in previous research [41] [61].

\section{Conclusions}

Verbal aggressiveness is presented in all classes, but the structural features are differentiated. Regarding network structures density is an appropriate indicator for depicting the perceived verbal aggressiveness, so it is useful to apply several indicators (katz, pagerank, etc.). All indicators seem to be correlated with certain non-network variables, but different indicators reveal different properties and 
meanings. The social meaning of five tested indicators (katz, pagerank, authority, indegree, outdegree) seems to converge in the present study. Also, the new indicators (incremental and proportional behavior), appear to express the pure aggressiveness. Using a wide range of network metrics (indegree, katz, pagerank, authority) discloses a respectively conscientious range of types depicting distinct structures and behaviors. As for the typology of the incremental and proportional behavior two types were proposed: a) the "personal attack" that the verbal aggressor aims the victims' personality and b) social exclusion that the strategy is to exclude the victim from the social surrounding.

Especially typologies seem to be practically useful for classifying or recognizing particular types of students more precisely and clearly. Such discrete types can thus be criteria for pedagogic planning and orientation of the teaching staff while the irrelevance of gender can help deconstruct prejudices (e.g. about the peacefulness of female students or the distinct aggressiveness of the male ones). Thus, the application of such mathematical application in the analysis of class relations using the particular indicators seems to create the expected added value.

Certain challenges for future research are to propose more elaborated network indicators for depicting more deep-rooted structures. Extensive focus groups and in-depth interviews with students and teaching staff can enable a deeper understanding of the quantitative results. A larger sample from more regions or other countries would also be conducive to a comparable analysis.

\section{References}

[1] Infante, D.A. and Wigley III, C.J. (1986) Verbal Aggressiveness: An Interpersonal Model and Measure. Communication Monographs, 53, 61-69. https://doi.org/10.1080/03637758609376126

[2] Bekiari, A. and Hasanagas, N. (2016) Sociological Insights in the Education System: "Unlocking" the Power Relations. Thessaloniki, AfoiKyriakidi Editions S.A.

[3] Bekiari, A. and Hasanagas, N. (2016) "Educating" in Physical Education. Theoretical Approaches and Practical Inquiries. Thessaloniki, AfoiKyriakidi Editions S.A.

[4] Bekiari, A., Kokaridas, D. and Sakellariou, K. (2005) Verbal Aggressiveness of Physical Education Teachers and Students' Self-Reports of Behaviour. Psychological Reports, 96, 493-498. https://doi.org/10.2466/pr0.96.2.493-498

[5] Bekiari, A. and Manoli, P. (2016) EFL Teacher Verbal Aggressiveness and Argumentativeness and Student Socio-Affective Strategy Use and Affective Learning: Exploring Possible Associations. Journal of Teacher Education and Educators, 5, 154-171.

[6] Infante, D.A. (1995) Teaching Students to Understand and Control Verbal Aggression. Communication Education, 44, 51-63. https://doi.org/10.1080/03634529509378997

[7] Myers, S.A., Edwards, C., Wahl, S.T. and Martin, M.M. (2007) The Relationship between Perceived Instructor Aggressive Communication and College Student Involvement. Communication Education, 56, 495-508.

https://doi.org/10.1080/03634520701466398

[8] Infante, D.A., Chandler, T.A. and Rudd, J.E. (1989) Test of an Argumentative Skill 
Deficiency Model of Interspousal Violence. Communications Monographs, 56, 163 177. https://doi.org/10.1080/03637758909390257

[9] Rocca, K.A. (2004) College Student Attendance: Impact of Instructor Immediacy and Verbal Aggression. Communication Education, 53, 185-195. https://doi.org/10.1080/03634520410001682447

[10] Bekiari, A. (2014) Verbal Aggressiveness and Leadership Style of Sports Instructors and Their Relationship with Athletes' Intrinsic Motivation. Creative Education, 5, 114-121. https://doi.org/10.4236/ce.2014.52018

[11] Bekiari, A. and Sakellariou, K. (2003) Perceived Instructor Verbal Aggressiveness and Student State Learning in Physical Education. Italian Journal of Sport Sciences, 1, 251-256.

[12] Bekiari, A. and Syrmpas, I. (2015) Coaches' Verbal Aggressiveness and Motivational Climate as Predictors of Athletes' Satisfaction. British Journal of Education, Society \& Behavioural Science, 9, 318-329. https://doi.org/10.9734/BJESBS/2015/17757

[13] Goodboy, A.K. and Bolkan, S. (2009) College Teacher Misbehaviors: Direct and Indirect Effects on Student Communication Behavior and Traditional Learning Outcomes. Western Journal of Communication, 73, 204-219. https://doi.org/10.1080/10570310902856089

[14] Rocca, K.A. (2008) Student Participation in the College Classroom: The Impact of Instructor Immediacy and Verbal Aggression. Journal of Classroom Interaction, 43, 22-33.

[15] Weiss, S.D. and Houser, M.L. (2007) Student Communication Motives and Interpersonal Attraction toward Instructor. Communication Research Reports, 24, 215 224. https://doi.org/10.1080/08824090701439091

[16] Buford, A.M. (2010) Perception Becomes Reality: Student-Teacher Relationships and Verbally Aggressive Messages. Master's Thesis, Cleveland State University, Cleveland.

[17] Schrodt, P. (2003) Student Perceptions of Instructor Verbal Aggressiveness: The Influence of Student Verbal Aggressiveness and Self-Esteem. Communication Research Reports, 20, 240-250. https://doi.org/10.1080/08824090309388822

[18] Bekiari, A., Perkos, S. and Gerodimos, V. (2015) Verbal Aggression in Basketball: Perceived Coach Use and Athlete Intrinsic and Extrinsic Motivation. Journal of Physical Education and Sport, 15, 96-102.

[19] Bekiari, A. and Petanidis, D. (2016) Exploring Teachers' Verbal Aggressiveness through Interpersonal Attraction and Students' Intrinsic Motivation. Open Journal of Social Sciences, 4, 72-85. https://doi.org/10.4236/jss.2016.412007

[20] Hasanagas, N. and Bekiari, A. (2015) Depicting Determinants and Effects of Intimacy and Verbal Aggressiveness Target through Social Network Analysis. Sociology Mind, 5, 162-175. https://doi.org/10.4236/sm.2015.53015

[21] Mazer, J.P. and Stowe, S.A. (2016) Can Teacher Immediacy Reduce the Impact of Verbal Aggressiveness? Examining Effects on Student Outcomes and Perceptions of Teacher Credibility. Western Journal of Communication, 80, 21-37.

[22] Bekiari, A., Patsiaouras, A., Kokaridas, D. and Sakellariou, K. (2006) Verbal Aggressiveness and State Anxiety of Volleyball Players and Coaches. Psychological Reports, 99, 630-634.

[23] Manoli, P. and Bekiari, A. (2015) EFL Teachers' Verbal Aggressiveness and Students' Intrinsic Motivation and Social-Affective Strategy Use: Investigating Possible Relations. Advances in Research, 5, 1-13. https://doi.org/10.9734/AIR/2015/19692

[24] Myers, S.A. (2002) Perceived Aggressive Instructor Communication and Student 
State Motivation, Learning, and Satisfaction. Communication Reports, 15, 113-121. https://doi.org/10.1080/08934210209367758

[25] Myers, S.A. and Knox, R.L. (2000) Perceived Instructor Argumentativeness and Verbal Aggressiveness and Student Outcomes. Communication Research Reports, 17, 299-309. https://doi.org/10.1080/08824090009388777

[26] Myers, S.A. and Rocca, K.A. (2001) Perceived Instructor Argumentativeness and Verbal Aggressiveness in the College Classroom: Effects on Student Perceptions of Climate, Apprehension, and State Motivation. Western Journal of Communication, 65, 113-137. https://doi.org/10.1080/10570310109374696

[27] Schrodt, P. (2003) Students' Appraisals of Instructors as a Function of Students' Perceptions of Instructors' Aggressive Communication. Communication Education, 52, 106-121. https://doi.org/10.1080/03634520302468

[28] Uludag, O. (2013) The Influence of Aggression on Students' Achievement: Evidence from Higher Education. Procedia-Social and Behavioral Sciences, 89, 954-958.

[29] Yaratan, H. and Uludag, O. (2012) The Impact of Verbal Aggression on Burnout: An Empirical Study on University Students. Procedia-Social and Behavioral Sciences, 46, 41-46.

[30] Bekiari, A. (2012) Perceptions of Instructors' Verbal Aggressiveness and Physical Education Students' Affective Learning. Perceptual and Motor Skills, 115, 325-335. https://doi.org/10.2466/06.11.16.PMS.115.4.325-335

[31] Bekiari, A. and Tsaggopoulou, Th. (2016) Verbal Aggressiveness and Affective Learning in Physical Education. Advances in Physical Education, 6, 406-418. https://doi.org/10.4236/ape.2016.64041

[32] Wrench, J.S. and Punyanunt-Carter, N.M. (2005) Advisor-Advisee Communication Two: The Influence of Verbal Aggression and Humor Assessment on Advisee Perceptions of Advisor Credibility and Affective Learning. Communication Research Reports, 22, 303-313. https://doi.org/10.1080/000368105000317599

[33] Infante, D.A., Hartley, K.C., Martin, M.M., Higgins, M.A., Bruning, S.D. and Hur, G. (1992) Initiating and Reciprocating Verbal Aggression: Effects on Credibility and Credited Valid Arguments. Communication Studies, 43, 182-190. https://doi.org/10.1080/10510979209368370

[34] Bekiari, A., Kokaridas, D. and Sakellariou, K. (2006) Associations of Students' Self-Reports of Their Teacher's Verbal Aggression, Intrinsic Motivation, and Perceptions of Reasons for Discipline in Greek Physical Education Classes. Psychological Reports, 98, 451-461. https://doi.org/10.2466/pr0.98.2.451-461

[35] Bekiari, A. and Pylarinou, M. (2017) Instructor Argumentativeness and SocioCommunicative Style and Student Discipline: Using Physical Education Students' Class as an Illustration. Open Journal of Social Sciences, 5, 122-136. https://doi.org/10.4236/jss.2017.53011

[36] Bekiari, A., Digelidis, N. and Sakellariou, K. (2006) Perceived Verbal Aggressiveness of Coaches in Volleyball and Basketball: A Preliminary Study. Psychological Reports, 103, 526-530.

[37] Rocca, K.A. and McCroskey, J.C. (1999) The Interrelationship of Student Ratings of Instructors' Immediacy, Verbal Aggressiveness, Homophily, and Interpersonal Attraction. Communication Education, 48, 308-316. https://doi.org/10.1080/03634529909379181

[38] Syrmpas, I. and Bekiari, A. (2015) The Relationship between Perceived Physical Education Teacher's Verbal Aggressiveness and Argumentativeness with Students' Interpersonal Attraction. Inquiries in Sport \& Physical Education, 13, 21-32. 
[39] Hassandra, M., Bekiari, A. and Sakellariou, K. (2007) Physical Education Teacher's Verbal Aggression and Student's Fair Play Behaviors. The Physical Educator, 64, 94-101.

[40] Bekiari, A. (2016) Insights into Instructors' Verbal Aggressiveness and Students' Machiavellianism through Leadership Style and Motivational Climate. European Scientific Journal, 12, 90-110. https://doi.org/10.19044/esj.2016.v12n25p90

[41] Bekiari, A., Pachi, V. and Hasanagas, N. (2017) Investigating Bullying Determinants and Typologies with Social Network Analysis. Journal of Computer and Communications, 5, 11-27. https://doi.org/10.4236/jcc.2017.57002

[42] Bekiari, A. and Tsiana, I. (2016) Exploring Instructors' Verbal Aggressiveness and Students' Personal Orientations and Reasons of Discipline in Physical Education Class. Advances in Physical Education, 6, 158-168.

https://doi.org/10.4236/ape.2016.63018

[43] Myers, S.A. and Rocca, K.A. (2000) The Relationship between Perceived Instructor Communicator Style, Argumentativeness, and Verbal Aggressiveness. Communication Research Reports, 17, 1-12. https://doi.org/10.1080/08824090009388745

[44] Avtgis, T.A. and Rancer, A.S. (2008) The Relationship between Trait Verbal Aggressiveness and Teacher Burnout Syndrome in K-12 Teachers. Communication Research Reports, 25, 86-89. https://doi.org/10.1080/08824090701831875

[45] Bekiari, A., Deliligka, S. and Koustelios, A. (2016) Examining Relations of Aggressive Communication in Social Networks. Social Networking, 6, 38-52.

https://doi.org/10.4236/sn.2017.61003

[46] Bekiari, A. and Hasanagas, N. (2015) Verbal Aggressiveness Exploration through Complete Social Network Analysis: Using Physical Education Students' Class as an Illustration. International Journal of Social Science Studies, 3, 30-49.

https://doi.org/10.11114/ijsss.v3i3.729

[47] Bekiari, A. and Hasanagas, N. (2016) Suggesting Indicators of Superficiality and Purity in Verbal Aggressiveness. An Application in Adult Education Class Networks of Prisoners. Open Journal of Social Sciences, 4, 279-292. https://doi.org/10.4236/jss.2016.43035

[48] Bekiari, A. and Spyropoulou, S. (2016) Exploration of Verbal Aggressiveness and Interpersonal Attraction through Social Network Analysis: Using University Physical Education Class as an Illustration. Open Journal of Social Sciences, 4, 145-155. https://doi.org/10.4236/jss.2016.46016

[49] Theoharis, D., Bekiari, A. and Koustelios, A. (2017) Exploration of Determinants of Verbal Aggressiveness and Leadership through Network Analysis and Conventional Statistics. Using School Class as an Illustration. Sociology Mind, 7, 27-43. https://doi.org/10.4236/sm.2017.72003

[50] Scott, J. (2000) Social Network Analysis: A Handbook. 2nd Edition, Sage Publications, London.

[51] Wasserman, S. and Faust, K. (1994) Social Network Analysis: Methods and Applications. Cambridge University Press, Cambridge, England.

https://doi.org/10.1017/CBO9780511815478

[52] Bekiari, A., Deliligka, S. and Hasanagas, N. (2017) Analyzing Networks of Verbal Aggressiveness and Motivation. Psychology, 8, 495-515.

https://doi.org/10.4236/psych.2017.83031

[53] Bekiari, A., Hasanagas, N., Theoharis, D., Kefalas, I. and Vasilou, A. (2015) The Role of Mathematical Object and the Educational Environment to Students' Interpersonal Relationships: An Application of Full Social Network Analysis. Proceed- 
ings of the 32 nd Congress Greek Mathematical Society (with International Participation), Kastoria, 799-812.

[54] Hasanagas, N. and Bekiari, A. (2017) An Exploration of the Relation between Hunting and Aggressiveness: Using Inmates Networks at Prison Secondary School as an Illustration. Social Networking, 6, 19-37. https://doi.org/10.4236/sn.2017.61002

[55] Theoharis, D. and Bekiari, A. (2016) The Influence of Mathematics and Learning Environment in Verbal Aggressiveness and Interpersonal Relations: A Dynamic Analysis of Social Networks. Proceedings of the 8 th International Congress Mathematical Society, Thessaloniki, 30 March-3 April 2016, 415-428.

[56] Theoharis, D. and Bekiari, A. (2016) Social Networks Analysis of Centrality: Case Study in Leadership Networks. Proceedings of the 33nd Congress Greek Mathematical Society (with International Participation), Chania, 4-6 November 2016, 250-260.

[57] Theoharis, D. and Bekiari, A. (2017) Cumulative Hierarchy Analysis (Katz Centrality) on Leadership Networks of Learning Communities. Proceedings of the 9 th International Congress Mathematical Society, Thessaloniki, 17-19 March 2017, 285297.

[58] Farmakis, N. (2000) Introduction to Sampling. Christodoulidis, Thessaloniki.

[59] Bekiari, A. and Digelidis, N. (2015) Measuring Verbal Aggressiveness in Sport and Education. International Journal of Physical Education, 52, 12-21.

[60] Field, A. (2009) Discovering Statistics Using IBM SPSS Statistics. 3th Edition, SAGE Publications Ltd., Thousand Oaks, CA.

[61] Bekiari, A., Nikolaidou, Z.A. and Hasanagas, N. (2017) Typology of Motivation and Aggression on the Basis of Social Network Variables: Examples of Complementary and Nested Behavioral Types through Conventional Statistics. Social Networking, 6, 135-147. http://www.scirp.org/journal/sn https://doi.org/10.4236/sn.2017.62008

\section{Scientific Research Publishing}

\section{Submit or recommend next manuscript to SCIRP and we will provide best service for you:}

Accepting pre-submission inquiries through Email, Facebook, LinkedIn, Twitter, etc. A wide selection of journals (inclusive of 9 subjects, more than 200 journals)

Providing 24-hour high-quality service

User-friendly online submission system

Fair and swift peer-review system

Efficient typesetting and proofreading procedure

Display of the result of downloads and visits, as well as the number of cited articles

Maximum dissemination of your research work

Submit your manuscript at: http://papersubmission.scirp.org/

Or contact jcc@scirp.org 